\title{
Management of diabetic macular edema patients in clinical practice in Spain
}

European Journal of Ophthalmology I-9

(C) The Author(s) 2018 Article reuse guidelines: sagepub.com/journals-permissions DOI: | 0.1 | 77/| | 20672 | I8804079 journals.sagepub.com/home/ejo

\section{(S)AGE}

\author{
Rodrigo Abreu-Gonzalez', Roberto Gallego-Pinazo², \\ Maximino Abraldes ${ }^{3}$, Isabel Pinilla ${ }^{4}$ \\ and María I Lopez-Galvez ${ }^{5}$; DME Challenge Group
}

\begin{abstract}
Purpose: Diabetic macular edema is the main cause of blindness in diabetic patients. Vascular endothelial growth factor is involved in diabetic macular edema pathogenesis. Vascular endothelial growth factor inhibitors are an important option in diabetic macular edema therapy. This survey investigates actual clinical practice in diabetic macular edema in Spain.

Methods: An expert advisory panel of 17 Spanish ophthalmologists developed a 30-item anonymous questionnaire about diagnosis, treatment, and follow-up in diabetic macular edema. A total of I37 ophthalmologists from I0 Spanish regions completed the questionnaire online.

Results: Almost all of the respondents (99.3\%) record the measured visual acuity and perform biomicroscopic anterior (94.9\%) and posterior (91.2\%) segment examinations. Similarly, 100\% of responding ophthalmologists always/ almost always or frequently perform optical coherence tomography. Most respondents (65\%) always/almost always or frequently perform a retinography. More than $50 \%$ rarely perform fluorescein angiography. Nearly, all ( $96.4 \%)$ of the specialists responded that, in center-involved diabetic macular edema, the first treatment is an anti-vascular endothelial growth factor drug. For corticosteroids, the first choice of most respondents (91.2\%) was the dexamethasone implant. In the follow-up, almost all (96.4\%) specialists record the measured visual acuity and most also perform biomicroscopic anterior (82.5\%) and posterior (83.2\%) segment examination.

Conclusion: This survey shows the actual clinical practice in diabetic macular edema in Spain, finding that anti-vascular endothelial growth factor therapy is frequently used, and that diagnosis, treatments, and follow-up examinations used by specialists are homogeneous and according to diabetic macular edema guidelines.
\end{abstract}

\section{Keywords}

Anti-vascular endothelial growth factor, clinical practice, diabetic macular edema, optical coherence tomography

Date received: 7 November 2017; accepted: 24 February 2018

\section{Introduction}

More than 400 million adults suffer from diabetes mellitus (DM) worldwide. The most common microvascular complication of DM is diabetic retinopathy (DR), which is characterized by progressive retinal microvascular changes leading to tissue ischemia, increased permeability, neovascularization, and edema. ${ }^{1}$ When the macula (the center area of the retina) is affected, the patient is considered to have diabetic macular edema (DME), which is one of the leading causes of visual impairment in diabetics and a common cause of blindness in the working-age population in most developed countries. ${ }^{2}$

Approximately, $25 \%$ of patients with DM have some degree of DR and from $2 \%$ to $10 \%$ present DME. ${ }^{3}$ The
'Ophthalmology Center, University Hospital of La Candelaria, Tenerife, Spain

${ }^{2}$ Oftalvist Clinic, Valencia, Spain

${ }^{3}$ Gómez-Ulla Ophthalmological Institute and University Hospital of Santiago de Compostela, Santiago de Compostela, Spain

${ }^{4}$ Aragon Health Sciences Institute, Lozano Blesa University Hospital, Zaragoza, Spain

5IOBA and University Clinic Hospital of Valladolid, Valladolid, Spain

\section{Corresponding author:}

Rodrigo Abreu-Gonzalez, Ophthalmology Center, University Hospital of La Candelaria, Ctra. del Rosario, I45, 38010 Tenerife, Spain.

Email: rodrigoabreug@gmail.com 
incidence of DME among diabetics in Spain is $2.2 \%$. A recent study found that the incidence rate increased from 2007 to 2014, especially in patients between 31 and 70 years of age. ${ }^{4}$

The gold standard for treatment of focal DME has long been laser photocoagulation. However, in diffuse macular edema, laser photocoagulation has yielded poor results. For this reason, alternative treatments based on the pathogenesis of DME have been sought. Studies on the pathophysiology of DME suggest that vascular endothelial growth factor (VEGF) and inflammatory cytokines play a crucial role in the development of the disease. ${ }^{5}$ Based on those findings, multicenter randomized clinical trials (RCTs) have been conducted to evaluate the value of intravitreal corticosteroids and anti-VEGF agents in the management of DME. ${ }^{6-8}$

Despite the availability of effective treatment modalities, numerous barriers - including financial, sociological, educational, and psychological factors - to optimal care remain. In this context, an optimal approach to diagnosing and managing patients with DME has not been established in routine clinical practice, and more uniform criteria are needed. The aim of this survey was to elucidate the current clinical practice patterns (diagnosis, treatment, and followup) of DME management in Spain.

\section{Materials and methods}

An expert advisory panel of 17 Spanish ophthalmologists was constituted to evaluate the current status of clinical practice in Spain for DME. This expert panel developed a 30-item, anonymous online questionnaire (Table 1) which was sent to ophthalmologists of the public health system in Spain specialized in retinal ophthalmology. A total of 137 specialists from 10 of the 17 autonomous communities in Spain completed the questionnaire online at DME workshops in June 2016. Most of the respondents (62.8\%) had more than 10 years of experience as specialists in ophthalmology. More than $50 \%$ of specialists dedicated to the retina more than $75 \%$ of their practice time. This research has followed the tenets of the Declaration of Helsinki.

The questionnaire was divided into three sections: diagnosis (10 questions), treatment (9 questions), and followup (11 questions). Participants were instructed to give only one response to each question.

Descriptive statistics were used to interpret the data. The Statistical Package for the Social Sciences (SPSS) program, version 20.0 (IBM-SPSS; Chicago, IL; USA) was used to perform the statistical analysis.

\section{Results}

\section{Diagnosis}

Only $23.4 \%$ always/almost always record blood pressure data and $46.7 \%$ reported recording systemic treatments.
Most $(81.0 \%)$ of the respondents reported recording the type of diabetes and its duration (Table 2).

Almost all of the respondents (99.3\%) record the measured visual acuity and perform biomicroscopic anterior (94.9\%) and posterior (91.2\%) segment examinations. Similarly, $100 \%$ of responding ophthalmologists always/ almost always or frequently perform optical coherence tomography (OCT). Most respondents (65\%) always/almost always or frequently perform a retinography. More than $50 \%$ rarely perform fluorescein angiography (FA) (Table 2).

\section{Treatment}

In center-involved DME, $49.6 \%$ of respondents indicated that their patients begin treatment within 7 days after diagnosis, $40.9 \%$ within 30 days, $5.1 \%$ immediately, and $4.4 \%$ $>30$ days after diagnosis.

Nearly, all (96.4\%) of the specialists responded that, in center-involved DME, the first treatment is an antiVEGF drug. Most respondents (75.9\%) use ranibizumab $\left(\right.$ Lucentis $^{\circledR}$ ), with the most common regimen $(67.2 \%)$ being three injections (Figure 1).

For corticosteroids, the first choice of most respondents $(91.2 \%)$ was dexamethasone $\left(\right.$ Ozurdex $\left.^{\circledR}\right)$, followed by triamcinolone (Triesence ${ }^{\circledR}, 4.4 \%$; Trigon ${ }^{\circledR}, 3.6 \%$ ) in $8.0 \%$; or another corticosteroid in $0.7 \%$ of cases. Laser photocoagulation was used as follows: frequently $(26.3 \%)$, rarely (66.4\%), and never/almost never (7.3\%).

In patients with comorbid DME and proliferative retinopathy, the most common treatment $(84.7 \%)$ is anti-VEGF plus panretinal photocoagulation (PRP), followed by antiVEGF alone (9.5\%), PRP alone (2.9\%), and "other" treatments $(2.9 \%)$.

\section{Follow-up}

The majority (89.1\%) of participants responded that they always/almost always or frequently record changes in metabolic control parameters (Table 2). Almost all (96.4\%) specialists record the measured visual acuity and most specialists also perform biomicroscopic anterior $(82.5 \%)$ and posterior $(83.2 \%)$ segment examination. Just over half $(50.4 \%)$ always/almost always or frequently perform retinography and all (100\%) always/almost always or frequently perform an OCT. More than $80 \%$ rarely or never/ almost never administer FA (Table 2).

Nearly, all (97.8\%) of participants reported that they always/almost always or frequently carry out an examination with dilated pupil at each visit. The most common schedule for follow-up visits is every $1-3$ months $(57.7 \%$ of respondents) (Table 2).

\section{Discussion}

In this study, we sought to determine the clinical practice patterns (diagnosis, treatment and follow-up) that retinal 
Table I. Questionnaire structure.

\begin{tabular}{|c|c|c|}
\hline Classification & Questions & Possible responses \\
\hline Diagnosis & $\begin{array}{l}\text { I. Recording of metabolic control } \\
\text { 2. Recording of blood pressure } \\
\text { 3. Recording of systemic treatment } \\
\text { 4. Recording of diabetes type and duration } \\
\text { 5. Recording of measured visual acuity } \\
\text { 6. Biomicroscopic examination of the anterior segment } \\
\text { 7. Biomicroscopic examination of the posterior segment } \\
\text { 8. Retinography } \\
\text { 9. OCT } \\
\text { 10. Fluorescein angiography }\end{array}$ & $\begin{array}{l}\text { Always/almost always } \\
\text { Frequently } \\
\text { Rarely } \\
\text { Never/almost never }\end{array}$ \\
\hline \multirow[t]{9}{*}{ Treatment } & $\begin{array}{l}\text { II. In center-involved DME, the visual acuity at which } \\
\text { treatment is initiated }\end{array}$ & $\begin{array}{l}\text { Any } \\
<0.80-0.90 \\
<0.60-0.70 \\
<0.50\end{array}$ \\
\hline & $\begin{array}{l}\text { 12. In center-involved DME, the first treatment is } \\
\text { administered ... }\end{array}$ & $\begin{array}{l}\text { Immediately } \\
\text { Within } 7 \text { days } \\
\text { Within } 30 \text { days } \\
\text { More than } 30 \text { days after diagnosis }\end{array}$ \\
\hline & I3. In center-involved DME, the first-line treatment is ... & $\begin{array}{l}\text { Topical NSAID } \\
\text { Anti-VEGF } \\
\text { Corticosteroid } \\
\text { Photocoagulation }\end{array}$ \\
\hline & 14. The first choice for anti-VEGF treatment & $\begin{array}{l}\text { Bevacizumab }\left(\text { Avastin }^{\circledR}\right) \\
\text { Aflibercept }\left(\text { Eylea }^{\circledR}\right) \\
\text { Ranibizumab }\left(\text { Lucentis }^{\circledR}\right) \\
\text { Another }\end{array}$ \\
\hline & 15. Initial anti-VEGF regimen & $\begin{array}{l}\text { Three injections } \\
\text { PRN regime } \\
\text { Fact-sheet recommendation } \\
\text { Other }\end{array}$ \\
\hline & 16. If corticosteroids are used, the first drug is ... & $\begin{array}{l}\text { Triamcinolone }\left(\text { Triesence }{ }^{\circledR}\right) \\
\text { Triamcinolone }\left(\text { Trigon }^{\circledR}\right) \\
\text { Dexamethasone }\left(\text { Ozurdex }^{\circledR}\right) \\
\text { Other }\end{array}$ \\
\hline & 17. Frequency of laser photocoagulation & $\begin{array}{l}\text { Always/almost always } \\
\text { Frequently } \\
\text { Rarely } \\
\text { Never/almost never }\end{array}$ \\
\hline & $\begin{array}{l}\text { 8. In comorbid DME plus proliferative retinopathy, the } \\
\text { approach is ... }\end{array}$ & $\begin{array}{l}\text { To treat the retinopathy first } \\
\text { To treat the macular edema first }\end{array}$ \\
\hline & $\begin{array}{l}\text { 19. In comorbid DME plus proliferative retinopathy, the } \\
\text { treatment approach is ... }\end{array}$ & $\begin{array}{l}\text { Anti-VEGF } \\
\text { Anti-VEGF + PRP } \\
\text { PRP } \\
\text { Another }\end{array}$ \\
\hline \multirow[t]{2}{*}{ Follow-up } & $\begin{array}{l}\text { 20. Recording of metabolic control } \\
\text { 21. Recording of blood pressure } \\
\text { 22. Recording of systemic treatment } \\
\text { 23. Recording of visual acuity } \\
\text { 24. Biomicroscopic examination of the anterior segment } \\
\text { 25. Biomicroscopic examination of the posterior segment } \\
\text { 26. Retinography } \\
\text { 27. OCT } \\
\text { 28. Fluorescein angiography } \\
\text { 29. Examination with dilated pupil at each visit }\end{array}$ & $\begin{array}{l}\text { Always/Almost always } \\
\text { Frequently } \\
\text { Rarely } \\
\text { Never/Almost never }\end{array}$ \\
\hline & $\begin{array}{l}\text { 30. Frequency of follow-up visits during the treatment } \\
\text { period }\end{array}$ & $\begin{array}{l}\text { I month } \\
\mathrm{I}-3 \text { months } \\
>3 \text { months } \\
\text { Progression }\end{array}$ \\
\hline
\end{tabular}

OCT: optical coherence tomography; DME: diabetic macular edema; NSAID: non-steroidal anti-inflammatory drug; VEGF: vascular endothelial growth factor; PRN: pro re nata; PRP: panretinal photocoagulation. 
Table 2. Survey results: diagnosis and follow-up of patients with diabetic macular edema.

\begin{tabular}{|c|c|c|c|}
\hline Question & Diagnosis (\%) & Responses & Follow-up (\%) \\
\hline \multirow{4}{*}{$\begin{array}{l}\text { Recording of metabolic } \\
\text { control }\end{array}$} & 61.3 & Always/almost always & 40.9 \\
\hline & 28.5 & Frequently & 48.2 \\
\hline & 9.5 & Rarely & 8.8 \\
\hline & 0.7 & Never/almost never & 2.2 \\
\hline \multirow{4}{*}{$\begin{array}{l}\text { Recording of blood } \\
\text { pressure }\end{array}$} & 23.4 & Always/almost always & 13.9 \\
\hline & 31.4 & Frequently & 25.5 \\
\hline & 35.8 & Rarely & 43.8 \\
\hline & 9.5 & Never/almost never & 16.8 \\
\hline \multirow{4}{*}{$\begin{array}{l}\text { Recording of systemic } \\
\text { treatment }\end{array}$} & 46.7 & Always/almost always & 36.5 \\
\hline & 29.9 & Frequently & 29.2 \\
\hline & 17.5 & Rarely & 24.8 \\
\hline & 5.8 & Never/almost never & 9.5 \\
\hline \multirow{4}{*}{$\begin{array}{l}\text { Recording of diabetes } \\
\text { type and duration }\end{array}$} & 81.0 & Always/almost always & \\
\hline & 13.9 & Frequently & \\
\hline & 4.4 & Rarely & \\
\hline & 0.7 & Never/almost never & \\
\hline \multirow{4}{*}{$\begin{array}{l}\text { Recording of measured } \\
\text { visual acuity }\end{array}$} & 99.3 & Always/almost always & 96.4 \\
\hline & 0.7 & Frequently & 2.9 \\
\hline & 0 & Rarely & 0 \\
\hline & 0 & Never/almost never & 0.7 \\
\hline \multirow{4}{*}{$\begin{array}{l}\text { Biomicroscopic } \\
\text { examination of the } \\
\text { anterior segment }\end{array}$} & 94.9 & Always/almost always & 82.5 \\
\hline & 4.4 & Frequently & 14.6 \\
\hline & 0.7 & Rarely & 2.2 \\
\hline & 0 & Never/almost never & 0.7 \\
\hline \multirow{4}{*}{$\begin{array}{l}\text { Biomicroscopic } \\
\text { examination of the } \\
\text { posterior segment }\end{array}$} & 91.2 & Always/almost always & 83.2 \\
\hline & 6.6 & Frequently & 11.7 \\
\hline & 2.2 & Rarely & 4.4 \\
\hline & 0 & Never/almost never & 0.7 \\
\hline \multirow[t]{4}{*}{ Retinography } & 29.9 & Always/almost always & 19.7 \\
\hline & 35.8 & Frequently & 30.7 \\
\hline & 28.5 & Rarely & 45.3 \\
\hline & 5.8 & Never/almost never & 4.4 \\
\hline \multirow[t]{4}{*}{ OCT } & 86.9 & Always/almost always & 89.8 \\
\hline & 13.1 & Frequently & 10.2 \\
\hline & 0 & Rarely & 0 \\
\hline & 0 & Never/almost never & 0 \\
\hline \multirow{4}{*}{$\begin{array}{l}\text { Fluorescein } \\
\text { angiography }\end{array}$} & 8.0 & Always/almost always & 0 \\
\hline & 35.8 & Frequently & 19.7 \\
\hline & 51.8 & Rarely & 73.0 \\
\hline & 4.4 & Never/almost never & 7.3 \\
\hline \multirow{4}{*}{$\begin{array}{l}\text { Examination with } \\
\text { dilated pupil at each } \\
\text { visit }\end{array}$} & & Always/almost always & 77.4 \\
\hline & & Frequently & 20.4 \\
\hline & & Rarely & 1.5 \\
\hline & & Never/almost never & 0.7 \\
\hline \multirow{4}{*}{$\begin{array}{l}\text { Frequency of follow- } \\
\text { up visits during the } \\
\text { treatment period }\end{array}$} & & I month & 24.1 \\
\hline & & I-3 months & 57.7 \\
\hline & & $>3$ months & 4.4 \\
\hline & & Progression & 13.9 \\
\hline
\end{tabular}

OCT: optical coherence tomography.

specialists for the public health system in Spain use to manage DME. Our main findings were that the approach to diagnosis and follow-up is relatively homogeneous among specialists in Spain, and is consistent with current treatment guidelines. In addition, this survey confirms the important role of anti-VEGF therapy to treat DME. 


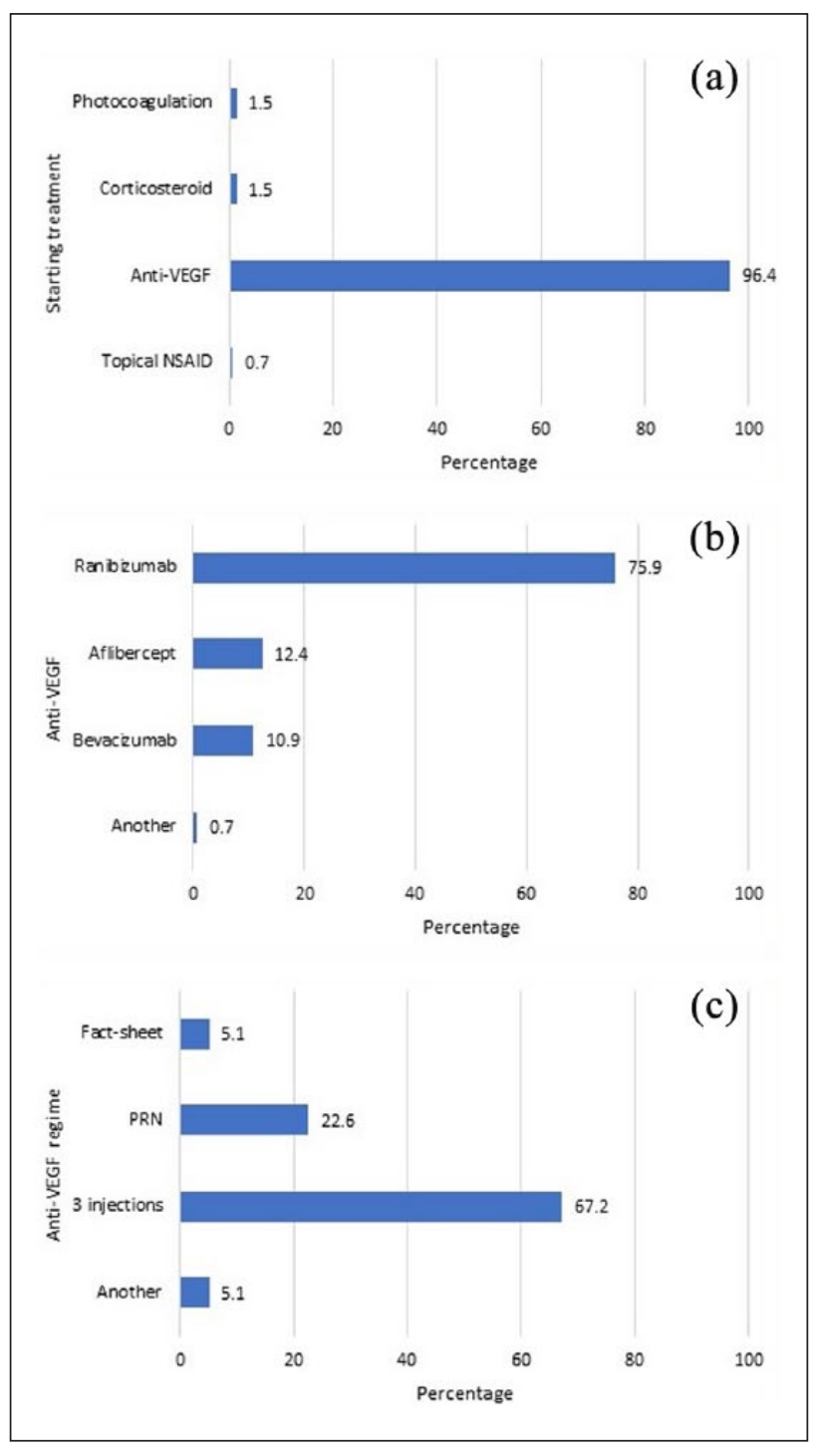

Figure I. Survey results on treatment of center-involved DME (a), anti-VEGF type (b), and treatment regime (c). NSAID: Non-steroidal anti-inflammatory drug. PRN: pro re nata.

\section{Diagnosis}

As the present survey confirms, there is substantial variability and debate among retinal specialists with regard to the optimal diagnostic process for DME. Several imaging techniques and other tests can be used to help identify and measure the clinical features of DME, including best corrected visual acuity (BCVA), biomicroscopic fundus examination, FA, retinography, and OCT. Although FA has long been the gold standard in the diagnosis of DME, OCT is increasingly used as a diagnostic modality for DME because it allows clinicians to accurately assess both the type and severity of DME and to non-invasively perform post-treatment follow-up. ${ }^{9,10}$

As part of the diagnostic process, close to $100 \%$ of the surveyed specialists reported that they usually measure visual acuity and perform an OCT and biomicroscopic examination of the anterior and posterior segments. In addition, $>60 \%$ perform a retinography (either frequently or always/almost always). By contrast, FA is used rarely or never by $>50 \%$ of specialists, a finding that can be explained by the decrease in the use of focal laser surgery in recent years, which has led to a reduction in the need for angiography to locate leaking microaneurysms or areas of capillary dropout.

A recent study on the clinical practice patterns in the management of DME in Japan ${ }^{11}$ found that $70.6 \%$ of specialists used OCT in combination with FA and fundus examination. As complementary tests, the results of OCT and FA are critical for therapeutic decision-making.

\section{Treatment}

Prior to performing invasive diagnostic procedures and/or starting treatment, all of the ophthalmologists surveyed in this study indicate that they first assess the patient's pertinent medical history and then perform relevant preoperative examinations to better characterize the patient's condition.

With regard to systemic treatments, most ophthalmologists surveyed here indicate that they usually record these data, especially with regard to metabolic control and treatment data. Although no definitive evidence is available with regard to the role of controlling systemic factors in DME, ophthalmologists should be in close consultation with the internist to assure that blood glucose levels, blood pressure, and blood lipids are all closely monitored and well controlled. ${ }^{12}$ Although it is essential to monitor and control the patient's systemic metabolic values in DR, this has proven to be insufficient in cases with DME. For this reason, additional measures are needed to prevent vision loss in such patients.

Anti-VEGF agents. The traditional treatment for "clinicallysignificant macular edema" (CSME) has been laser photocoagulation. By contrast, in DME, results of laser therapy have been more disappointing, failing to halt progression in approximately $50 \%$ of cases. Consequently, the search for alternative treatments has become a priority. Although the pathogenic mechanisms implicated in DME are not yet well understood, the identification of VEGF involvement has opened up new lines of research. In recent years, intravitreal VEGF inhibitors have emerged as the preferred therapy in many DME cases. Indeed, results from multiple well-designed studies have demonstrated that intravitreal anti-VEGF agents are more effective in center-involved CSME than monotherapy with laser surgery. ${ }^{13-15}$

Given this background, it is not surprising to observe that virtually all of the specialists $(\approx 97 \%)$ in our study use anti-VEGF agents as the first-line treatment for centerinvolved DME, findings that are consistent with other reports. In a comparative study to evaluate patterns of care 
for DME among European and US ophthalmologists, the findings showed strong similarities in terms of the types of therapies used to treat DME. ${ }^{16}$ For new and existing patients, the authors found that $>55 \%$ of specialists used anti-VEGF therapy and that the next most common treatment $(20 \%-25 \%)$ was laser monotherapy. All other treatments, such as steroids and vitrectomy, are used in $<20 \%$ of patients with DME.

A more recent survey conducted in the year 2016 in Canada have reported that most Canadian retina specialists utilize anti-VEGF injections as first-line therapy to treat DME, ${ }^{17}$ in keeping with current evidence. ${ }^{18,19}$

Three anti-VEGF drugs, administered by intravitreal injection, have been tested in prospective RCTs in adult patients with type 1 or type 2 diabetes. The evidence from these clinical trials (RESTORE, RESOLVE, READ-2, RISE, RIDE, VIVID DME, and VISTA studies) $)^{20-24}$ to support these anti-VEGF therapies is robust. Recently, the Diabetic Retinopathy Clinical Research Network (DRCR. net) Protocol trial demonstrated that anti-VEGF therapy using bevacizumab (Avastin ${ }^{\circledR}$ ), ranibizumab (Lucentis ${ }^{\circledR}$ ), or aflibercept $\left(\right.$ Eylea $\left.^{\circledR}\right)$ is an effective treatment for centerinvolving CSME. Clinical trials in patients with DME have repeatedly shown that anti-VEGF therapy not only stabilizes but also restores vision in a substantial proportion of patients. ${ }^{25-27}$

The most commonly used anti-VEGF agent reported by the specialists in this survey was ranibizumab $(75.9 \%$ of respondents), followed by aflibercept (12.4\%) and bevacizumab $(10.9 \%)$, a finding that is in line with results of a study performed to assess patterns of care in France for the treatment of DME. ${ }^{28}$ In that study, for center-involved DME in phakic or pseudophakic eyes, the first choice of intravitreal treatment was ranibizumab. The predominance of ranibizumab use may be due to the fact that it received marketing authorization by the European Medicines Agency (EMA) in the year 2010 for DME, ${ }^{29} 4$ years later aflibercept was approved (in 2014). ${ }^{30}$ In Spain, ranibizumab and aflibercept are both approved for intravitreal injection. Bevacizumab, which is not approved for any ocular indication, is widely used for off-label treatment of DME in repackaged aliquots containing approximately $1 / 500$ th of the systemic dose used in cancer therapy. However, in the Japanese survey, most specialists (69.4\%) reported using aflibercept as the first-line anti-VEGF, followed by ranibizumab (27.8\%), ${ }^{11}$ largely due to the results of the DRCR.net Protocol trial.

A recent survey conducted in the year 2017 in the United States ${ }^{31}$ found that the European specialists preferred to use aflibercept (46.1\%) followed by ranibizumab $(27.6 \%)$ and bevacizumab (24.1\%), while in the United States, bevacizumab was the treatment used by the $67.7 \%$ of specialists. ${ }^{31}$

Determining when to start anti-VEGF treatment remains one of the most important clinical questions in the management of DME. We found wide variability in the timing of anti-VEGF treatment initiation (determined by changes in visual acuity), in patients with center-involved DME: approximately $1 / 3$ of specialists initiate treatment regardless of the visual acuity, $1 / 3$ start at values ranging from $0.80-0.90$, and $1 / 3$ when visual acuity is $<0.60$. In the French study, most specialists reported initiating DME treatment when visual acuity is $>0.5$ (Monoyer scale). ${ }^{28}$

Regardless of the treatment indication, there are essentially two regimens for administering anti-VEGF drugs: continuous and intermittent/as required (or pro re nata $(\mathrm{PRN})$ ). Most of the initial trials were conducted using the continuous regimen, with regular monthly injections administered over the course of 2 years (24 injections in total). Although this treatment regimen was effective in those trials, it is also expensive and inconvenient for both the patient and the healthcare provider. Numerous trials have evaluated PRN regimens, using a fairly similar approach consisting of three injections given over 3 months, followed by a clinical evaluation. Trials of this dosing regimen for DME have shown that, on average, seven injections are required in the first year of treatment, with results that are equivalent to those obtained with regular monthly injections..$^{32}$ More than two-thirds of the specialists in our survey reported using a three-injection anti-VEGF regimen to start; only $22.6 \%$ reported using the PRN regimen.

Intravitreal corticosteroids. Corticosteroids inhibit many of the processes involved in DME progression due to their anti-inflammatory properties ${ }^{33}$ and VEGF inhibition. ${ }^{34}$ The use of corticosteroids in ocular DME has become increasingly common in certain patient profiles, such as refractory DME. To prolong drug retention in the vitreous humor, several sustained-release systems have been developed, including injectable drug suspensions and biodegradable and non-biodegradable intravitreal implants; these formulations have the added benefit of reducing the number and frequency of injections. ${ }^{35,36}$

Three potent synthetic corticosteroids with similar chemical structures have been investigated as intravitreal treatments for DME: triamcinolone acetonide, dexamethasone, and fluocinolone acetonide. In addition to Ozurdex ${ }^{\circledR}$ (Allergan, Inc.; dexamethasone biodegradable implant), other sustained-release corticosteroid systems used intravitreally include the following: Trivaris ${ }^{\circledR}$ (Allergan, Inc.; triamcinolone acetonide suspension); Triesence ${ }^{\circledR}$ (Alcon; triamcinolone acetonide suspension); $\operatorname{Retisert}^{\mathbb{B}}$ (Bausch \& Lomb Inc.,; fluocinolone acetonide non-biodegradable implant); and Iluvien ${ }^{\circledR}$ (Alimera Sciences, Inc.; fluocinolone acetonide non-biodegradable implant).

In our survey, the most commonly used first-line corticosteroid ( $>90 \%$ of respondents) was Ozurdex ${ }^{\circledR}$, but the survey design does not allow us to determine the overall use of corticosteroids. Intravitreal implants have been 
introduced recently, but studies conducted to assess the effectiveness of steroids have reported mixed results. ${ }^{10}$ Although there is evidence to support the use of intravitreal steroids in DME, 28,37 there is no clear consensus about whether these should be used as first-line therapy or for refractory cases. Despite their high rates of adverse effects, steroids may also be considered for patients who do not adequately respond to anti-VEGFs, as noted in the European licensing approval for fluocinolone, which states that this drug should be used only when other therapies have not had sufficient effect. ${ }^{38-40}$

Ogura et al. ${ }^{11}$ found that more than $10 \%$ of specialists choose sub-Tenon's corticosteroid injections as first-line therapy for diffuse DME and that corticosteroids are often preferred for ongoing DME therapy after vitrectomy. Although the use of corticosteroids in long-term DME therapy needs to be clarified, a recent study in patients with diffuse DME showed a reduction in the frequency of intravitreal bevacizumab administration when posterior sub-Tenon injection of triamcinolone was used. ${ }^{41}$

Coexistence of DME and proliferative retinopathy. In patients with both DME and proliferative retinopathy, most specialists (62.8\%) treat the DME first - as in Ogura's survey (84.2\% of respondents) - and the majority $(84.7 \%)$ use anti-VEGF plus PRP. ${ }^{14}$ In our survey, nearly all of the specialists reported using the combination of anti-VEGF and PRP to treat patients with comorbid DME and proliferative retinopathy. Thus, although monotherapy macular laser treatment seems to have lost its role as the gold standard treatment for center-involving DME, it may still play an important role when combined with anti-angiogenics by helping to reduce macular thickness and the number of injections needed. ${ }^{42-44}$

\section{Follow-up}

To evaluate treatment effectiveness, it is important to assess both the improvement in visual acuity and the structural changes induced by treatment. In this sense, OCT provides an objective and reproducible measure of retinal thickness and intraretinal structure, and for this reason, OCT has been used to evaluate and monitor treatment outcomes. ${ }^{45}$

In general, the follow-up evaluation includes both a medical history and an ophthalmic examination. The frequency of follow-up visits is in most cases every 1-3 months, and the examinations are similar to those used for diagnosis: visual acuity, slit-lamp biomicroscopy, stereoscopic examination of the pole after pupil dilation, and OCT imaging. Follow-up care should be performed according to standard practice guidelines. ${ }^{46-48}$

This survey reveals the real-life clinical management practices for DME in Spain today. However, this study has several limitations. First, we only surveyed a relatively small sample of ophthalmologists in Spain, and thus, the data are limited. For this reason, these findings cannot be generalized to the broader community based on this study alone. In addition, this study does not provide a complete picture of specialist practices in Spain because it only includes specialists from 10 of the 17 autonomous regions in Spain; moreover, there may be differences in the Spanish healthcare system from one region to the next that could have affected responses; for example, the high cost of antiVEGF treatment could lead to regional differences. Finally, the questionnaire was developed by a small team and thus necessarily reflects their biases; moreover, respondents were given only limited response options and thus their answers may not fully reflect their beliefs and/or clinical practices.

In conclusion, this survey of 137 ophthalmologists of the public health system in Spain was performed to assess the real-life clinical practice of retinal specialists in the treatment of DME. The main finding of this survey is that anti-VEGF therapy is commonly used to treat DME and that the approach to diagnosis and follow-up is relatively homogeneous among specialists in Spain and adheres to current DME treatment guidelines. The clinical pattern of diagnosis and treatment correspond closely to Spanish guidelines and other expert recommendations for the management of DME.

Anti-VEGF therapies are now considered the gold standard in the treatment of DME, and these medications are used in combination with laser treatment in numerous countries, including Spain, the United States, Canada, the United Kingdom, Switzerland, Germany, and France. In countries with universal healthcare, the high price of VEGF inhibitors such as ranibizumab and aflibercept does not appear to represent a barrier to prescription of these medical therapies to treat DME.

\section{Acknowledgements}

DME Challenge Group: Emilio Abecia Martínez, University Hospital Miguel Servet, Zaragoza, Spain; Maximino J Abraldes López-Veiga, University Hospital of Santiago de Compostela, Santiago de Compostela, Galicia, Spain; Rodrigo Abreu-Gonzalez, University Hospital of La Candelaria, Tenerife, Islas Canarias, Spain; Carlos Beckford Törngren, University Hospital Príncipe de Asturias, Alcalá De Henares, Madrid, Spain; Anna Boixadera Espax, University Hospital Vall d'Hebrón, Barcelona, Cataluña, Spain; Verónica Castro, General Hospital Enrique Cervera Taulet of Valencia, Valencia, Spain; Juan Donate López, Clinic Hospital San Carlos Madrid, Madrid, Spain; José Juan Escobar Barranco, Hospital Dos de Maig, Barcelona, Cataluña, Spain; Roberto Gallego-Pinazo, University and Polytechnic Hospital La Fe of Valencia, Valencia, Spain; Francisco Javier Lavid de los Mozos, Hospital Punta de Europa Algeciras, Cádiz, Andalucía, Spain; Maribel López Gálvez Clinic University Hospital of Valladolid, Valladolid, Castilla y León, Spain; José Luis Olea Vallejo, University Hospital Son Espases, Palma De Mallorca, Baleares, Spain; Sergio Pérez Torres, University Hospital Donostia, San 
Sebastián, País Vasco, Spain; Isabel Pinilla Lozano, Clinic University Hospital Lozano Blesa, Zaragoza, Aragón, Spain; Pere Romero Aroca, University Hospital Sant Joan de Reus, Tarragona, Cataluña, Spain; Marc Rubio Caso, University Hospital of Bellvitge, Barcelona, Cataluña, Spain; Xavier Valldeperas, Belmonte University Hospital Germans Tries i Pujol, Badalona, Cataluña, Spain. Thanks to Novartis Pharmaceutical S.A. for the DME Challenge Group meeting in which the discussion of this article was originated. All decisions about the content of the article have been taken by the authors. All authors have approved the final version of the manuscript.

\section{Declaration of conflicting interests}

The author(s) declared the following potential conflicts of interest with respect to the research, authorship, and/or publication of this article: R.A.-G. collaborated as a consultant/advisor and lecturer, receiving honoraria from Novartis; and as a consultant/advisor for Bayer. R.G.-P. collaborated as a consultant/advisor and lecturer, receiving honoraria and research funding from Novartis; and receiving research funding from Bayer; and as a lecturer, receiving honoraria and research funding from Heidelberg Engineering; and receiving research funding from Hoffman La Roche; and receiving research funding from Alcon; and receiving research funding from Thea. M.A. collaborated as a consultant/advisor and lecturer, receiving honoraria; and as a consultant/advisor for Bayer; and as a consultant/advisor for Allergan. I.P. collaborated as a consultant/advisor and lecturer, receiving honoraria from Novartis. M.I.L.-G. collaborated as a consultant/advisor and lecturer, receiving honoraria from Novartis; and as a consultant/advisor for Bayer; and as a lecturer, receiving honoraria from Lilly; and as a lecturer, receiving honoraria from Boehringer.

\section{Funding}

The author(s) received no financial support for the research, authorship, and/or publication of this article.

\section{References}

1. Wu L, Fernandez-Loaiza P, Sauma J, et al. Classification of diabetic retinopathy and diabetic macular edema. World $J$ Diabetes 2013; 4: 290-294.

2. Bourne RRA, Stevens GA, White RA, et al. Causes of vision loss worldwide, 1990-2010: a systematic analysis. Lancet Glob Health 2013; 1: e339-e349.

3. Williams R, Airey M, Baxter H, et al. Epidemiology of diabetic retinopathy and macular oedema: a systematic review. Eye 2004; 18: 963-983.

4. Romero-Aroca P, de la Riva-Fernandez S, Valls-Mateu A, et al. Changes observed in diabetic retinopathy: eight-year follow-up of a Spanish population. Br J Ophthalmol 2016; 100: 1366-1371.

5. Funatsu H, Noma H, Mimura T, et al. Association of vitreous inflammatory factors with diabetic macular edema. Ophthalmology 2009; 116: 73-79.

6. Boyer DS, Hopkins JJ, Sorof J, et al. Anti-vascular endothelial growth factor therapy for diabetic macular edema. Ther Adv Endocrinol Metab 2013; 4: 151-169.

7. Elman MJ, Bressler NM, Qin H, et al. Expanded 2-year follow-up of ranibizumab plus prompt or deferred laser or triamcinolone plus prompt laser for diabetic macular edema. Ophthalmology 2011; 118: 609-614.

8. Elman MJ, Aiello LP, Beck RW, et al. Randomized trial evaluating ranibizumab plus prompt or deferred laser or triamcinolone plus prompt laser for diabetic macular edema. Ophthalmology 2010; 117: 1064-1077.e35.

9. Glassman AR, Beck RW, Browning DJ, et al. Comparison of optical coherence tomography in diabetic macular edema, with and without reading center manual grading from a clinical trials perspective. Invest Ophthalmol Vis Sci 2009; 50: 560-566.

10. Virgili G, Menchini F, Dimastrogiovanni AF, et al. Optical coherence tomography versus stereoscopic fundus photography or biomicroscopy for diagnosing diabetic macular edema: a systematic review. Invest Ophthalmol Vis Sci 2007; 48: 4963-4973.

11. Ogura Y, Shiraga F, Terasaki H, et al. Clinical practice pattern in management of diabetic macular edema in Japan: survey results of Japanese retinal specialists. Jpn J Ophthalmol 2017; 61: 43-50.

12. UK Prospective Diabetes Study (UKPDS) Group. Intensive blood-glucose control with sulphonylureas or insulin compared with conventional treatment and risk of complications in patients with type 2 diabetes (UKPDS 33). Lancet 1998; 352: 837-853

13. Blinder KJ, Dugel PU, Chen S, et al. Anti-VEGF treatment of diabetic macular edema in clinical practice: effectiveness and patterns of use (ECHO Study Report 1). Clin Ophthalmol 2017; 11: 393-401.

14. Ho AC, Scott IU, Kim SJ, et al. Anti-vascular endothelial growth factor pharmacotherapy for diabetic macular edema: a report by the American Academy of Ophthalmology. Ophthalmology 2012; 119: 2179-2188.

15. Thomas BJ, Shienbaum G, Boyer DS, et al. Evolving strategies in the management of diabetic macular edema: clinical trials and current management. Can J Ophthalmol 2013; 48: 22-30.

16. John EG and Harris JF. Comparison of diabetic macular edema treatment patterns and outcomes by European and US retina-treating ophthalmologists. US Ophthalmic Rev 2014; 7: 63-67.

17. Rayat JS, Grewal PS, Whelan J, et al. Canadian preference and trends survey results for anti-VEGF treatment of macular edema. Can J Ophthalmol 2016; 51(3): 233-237.

18. Mukkamala L, Bhagat N and Zarbin MA. Practical lessons from Protocol I for the management of diabetic macular edema. Dev Ophthalmol 2017; 60: 91-108.

19. Virgili G, Parravano M, Evans JR, et al. Anti-vascular endothelial growth factor for diabetic macular oedema: a network meta-analysis. Cochrane Database of Systematic Reviews 2017; 6: CD007419.

20. Do DV, Nguyen QD, Khwaja AA, et al. Ranibizumab for edema of the macula in diabetes study: 3-year outcomes and the need for prolonged frequent treatment. JAMA Ophthalmol 2013; 131: 139-145.

21. Massin P, Bandello F, Garweg JG, et al. Safety and efficacy of ranibizumab in diabetic macular edema (RESOLVE Study): a 12-month, randomized, controlled, double-masked, multicenter phase II study. Diabetes Care 2010; 33: 2399 2405. 
22. Mitchell P, Bandello F, Schmidt-Erfurth U, et al. The RESTORE study: ranibizumab monotherapy or combined with laser versus laser monotherapy for diabetic macular edema. Ophthalmology 2011; 118: 615-625.

23. Nguyen QD, Brown DM, Marcus DM, et al. Ranibizumab for diabetic macular edema: results from 2 phase III randomized trials: RISE and RIDE. Ophthalmology 2012; 119: 789-801.

24. Brown DM, Schmidt-Erfurth U, Do DV, et al. Intravitreal aflibercept for diabetic macular edema: 100-week results from the VISTA and VIVID Studies. Ophthalmology 2015; 122(10): 2044-2052.

25. Arevalo JF, Lasave AF, Wu L, et al. Intravitreal bevacizumab plus grid laser photocoagulation or intravitreal bevacizumab or grid laser photocoagulation for diffuse diabetic macular edema: results of the Pan-American Collaborative Retina Study Group at 24 months. Retina 2013; 33: 403-413.

26. Brown DM, Nguyen QD, Marcus DM, et al. Long-term outcomes of ranibizumab therapy for diabetic macular edema: the 36-month results from two phase III trials: RISE and RIDE. Ophthalmology 2013; 120: 2013-2022.

27. Korobelnik JF, Do DV, Schmidt-Erfurth U, et al. Intravitreal aflibercept for diabetic macular edema. Ophthalmology 2014; 121: 2247-2254.

28. Qu-Knafo L, Fajnkuchen F, Sarda V, et al. Étude des pratiques françaises dans la prise en charge de l'œdème maculaire diabétique. J Fr Ophtalmol 2016; 39: 521-526.

29. Lucentis $^{\circledR}$ (ranibizumab). EPAR summary, http://www. ema.europa.eu/docs/en_GB/document_library/EPAR_-_ Summary_for_the_public/human/000715/WC500043548. pdf (accessed 29 August 2017).

30. Eylea ${ }^{\circledR}$ (aflibercept).EPARsummary,http://www.ema.europa .eu/docs/en_GB/document_library/EPAR___Summary_for the_public/human/002392/WC500135745.pdf (accessed 29 August 2017).

31. American Society of Retina Specialists Preference and Trends (PAT) Survey 2017. https:// www.asrs.org/content/documents/2017-asrs-global-trends-in-retina-surveyresults.pdf (accessed 25 January 2018).

32. Yorston D. Anti-VEGF drugs in the prevention of blindness. Community Eye Health 2014; 27: 44-46.

33. Cáceres-del-Carpio J, Costa RD, Haider A, et al. Corticosteroids: triamcinolone, dexamethasone and fluocinolone. Dev Ophthalmo 2016; 55: 221-231.

34. Brooks HL Jr, Caballero S Jr, Newell CK, et al. Vitreous levels of vascular endothelial growth factor and stromalderived factor 1 in patients with diabetic retinopathy and cystoid macular edema before and after intraocular injection of triamcinolone. Arch Ophthalmol 2004; 122: 1801-1807.

35. Haller JA, Bandello F, Belfort R, et al. Randomized, shamcontrolled trial of dexamethasone intravitreal implant in patients with macular edema due to retinal vein occlusion. Ophthalmology 2010; 117: 1134-1146.e3.

36. Lazic R, Lukic M, Boras I, et al. Treatment of anti-vascular endothelial growth factor-resistant diabetic macular edema with dexamethasone intravitreal implant. Retina 2014; 34: 719-724.

37. Jeon $\mathrm{S}$ and Lee WK. Effect of intravitreal triamcinolone in diabetic macular edema unresponsive to intravitreal bevacizumab. Retina 2014; 34: 1606-1611.

38. Alimera Sciences' ILUVIEN ${ }^{\circledR}$ receives marketing authorization in France for the treatment of chronic diabetic macular edema, 18 July 2012, http://investor.alimerasciences .com/static-files/3ff5cb55-8275-456b-8f48-0c259282c225 (accessed 29 August 2017).

39. Campochiaro PA, Brown DM, Pearson A, et al. Long-term benefit of sustained-delivery fluocinolone acetonide vitreous inserts for diabetic macular edema. Ophthalmology 2011; 118: 626-635e2.

40. Public summary of opinion on orphan designation: fluocinolone acetonide for the treatment of non-infectious uveitis, http://www.ema.europa.eu/docs/en_GB/document_library /Orphan_designation/2016/05/WC500207485.pdf (Accessed 29 August 2017).

41. Shimura M, Yasuda K, Minezaki T, et al. Reduction in the frequency of intravitreal bevacizumab administrations achieved by posterior subtenon injection of triamcinolone acetonide in patients with diffuse diabetic macular edema. Jpn J Ophthalmol 2016; 60: 401-407.

42. Barteselli G, Kozak I, El-Emam S, et al. 12-month results of the standardised combination therapy for diabetic macular oedema: intravitreal bevacizumab and navigated retinal photocoagulation. Br J Ophthalmol 2014; 98: 1036-1041.

43. Chen G, Li W, Tzekov R, et al. Ranibizumab monotherapy or combined with laser versus laser monotherapy for diabetic macular edema: a meta-analysis of randomized controlled trials. PLoS ONE 2014; 9: e115797.

44. Hirano T, Toriyama Y, Iesato Y, et al. Effect of leaking perifoveal microaneurysms on resolution of diabetic macular edema treated by combination therapy using anti-vascular endothelial growth factor and short pulse focal/grid laser photocoagulation. Jpn J Ophthalmol 2017; 61: 51-60.

45. Otani $\mathrm{T}$ and Kishi S. Tomographic assessment of vitreous surgery for diabetic macular edema. Am J Ophthalmol 2000; 129: 487-494.

46. American Academy of Ophthalmology Retina/Vitreus Panel. Preferred practice pattern ${ }^{\circledR}$ guidelines (diabetic retinopathy). San Francisco, CA: American Academy of Ophthalmology, 2017, https://www.aao.org/preferred-practice-pattern/diabetic -retinopathy-ppp-updated-2017 (accessed 27 September 2018).

47. Bandello F, Midena E, Menchini U, et al. Recommendations for the appropriate management of diabetic macular edema: light on DME survey and consensus document by an expert panel. Eur J Ophthalmol 2016; 26: 252-261.

48. Pareja Ríos A and López Gálvez MI. Guías de práctica clínica de la SERV. Manejo de las complicaciones oculares de la diabetes (Retinopatía Diabética y Edema Macular. Segunda revision), 2015, https://serv.es/wp-content/descar gasWP/documentacionMedica/Guia_SERV_03_segunda Revision.pdf (accessed 29 August 2017). 